\title{
Large-Scale Experimental and Numerical Study of Blast Acceleration Created by Close-In Buried Explosion on Underground Tunnel Lining
}

\author{
Mohamad Reza Soheyli, ${ }^{1}$ A. H. Akhaveissy, ${ }^{2}$ and S. M. Mirhosseini ${ }^{1}$ \\ ${ }^{1}$ Department of Civil Engineering, Islamic Azad University, Arak Branch, Arak, Iran \\ ${ }^{2}$ Department of Civil Engineering, Razi University, Kermanshah, Iran \\ Correspondence should be addressed to A. H. Akhaveissy; ahakhaveissy@razi.ac.ir
}

Received 20 April 2016; Accepted 16 August 2016

Academic Editor: Isabelle Sochet

Copyright (C) 2016 Mohamad Reza Soheyli et al. This is an open access article distributed under the Creative Commons Attribution License, which permits unrestricted use, distribution, and reproduction in any medium, provided the original work is properly cited.

\begin{abstract}
Despite growing demands for structures in water transportation tunnels, underground installations, subsurface dams, and subterranean channels, there is limited field knowledge about the dynamic behavior of these structures in the face of nearfault earthquakes or impulse excitations. This study conducted a large-scale test on underground tunnel excited by two close-in subsurface explosions. The horizontal and vertical acceleration were recorded on the vertical wall of the tunnel and the free field data including the acceleration on the ground surface at 11-meter distance from the tunnel. The frequency domain analysis of recorded results determined the frequency $961 \mathrm{~Hz}$ and $968 \mathrm{~Hz}$ for $1.69 \mathrm{~kg}$ and $2.76 \mathrm{~kg}$ equivalent T.N.T., respectively. Then, finite element analysis results were compared with the test data. The comparisons demonstrated a good correlation and satisfied the field data. Finally, based on numerical modeling, a parametric study was applied to determine the effects of shear wave velocity distance of the crater with respect to the tunnel on impulse response of the tunnel.
\end{abstract}

\section{Introduction}

Underground RC (reinforced concrete) structures have numerous applications in water canals, transportation tunnels, military caches, auxiliary tunnels, and shelters. The high risk of underground explosions necessitates careful research on the response of underground RC structures to these events. The dynamic response of underground RC structures to underground explosions has been numerically studied by several researchers [1-3]. Lu et al. used 2- and 3 -dimensional numerical models to analyze the response of underground structures subjected to subsurface explosions which occurred in the soil medium. They discussed the general characteristics of the resulting blast and evaluated the accuracy of $2 \mathrm{D}$ and $3 \mathrm{D}$ models. They reported that $2 \mathrm{D}$ models could predict the blast wave in soil medium with an acceptable accuracy. They also found that 2D models could be used to acquire accurate predictions for the blast load and response of the front wall in subsurface structures
[4]. Gui and Chien presented the blast-resistant analysis for a tunnel passing beneath Taipei Shongshan Airport. They briefly discussed the overall analysis process to obtain the maximum lining thrust caused by a bomb explosion for use in the structural lining design. Their study used FLAC2D as the finite difference program. The TM 5-855-1 empirical formulae [5] for free field conditions were used for the validity of model parameters. The linear elastic-perfectly plastic Mohrcoulomb model was assumed for the soil [6]. The response of buried shelters was investigated to blast loadings due to conventional weapon detonation by using the finite element method by Yang. The finite element analysis was carried out using a commercial FEA software package, ABAQUS. The validity of finite element model parameters adopted was established through comparison with the existing empirical formulae for free field conditions in a soil half-space [7].

The use of experiments can help to understand the dynamic response of buried structures subjected to explosion, for different types of underground RC structures. 
Alekseenko and Rykov proposed a series of far-field experimental data and compared the parameters of stress waves in sandstone and clay ground when charges of $0.2 \mathrm{~kg}$ to $200 \mathrm{~kg}$ of T.N.T. exploded [8]. Grigoryan et al. experimentally investigated spherical blast waves in all basic types of soils and determined the stress components and particle velocity [9]. Yankelevsky et al. investigated the explosion characteristics of a cylindrical explosion which was buried in the soil close to a rigid obstacle. They examined the above procedure for the incident wave propagation and compared it with experimental results of an explosion in clay loam [10]. The experimental study by Vovk et al. considered the explosion pressure caused by a circular charge [11]. It only provided the test data and did not discuss the data recording instruments. An investigated the soil behavior under blast loading using finite element method and showed that numerical results were validated by empirical results. In the empirical method, the cylindrical tank, made of a thick steel pipe, was filled with the test soil. C4 explosive charge was placed at $3 \mathrm{~cm}$ depth in the soil at the center of the tank. In this test, nine "pencil" pressure transducers measured air pressure of the buried explosions [12]. Chen et al. performed a theoretical study on dynamic responses of underground $\mathrm{RC}$ arch structures subjected to localized blast loads. The structure model was a circular arch with two side walls and a floor slab. Side walls were $1.15 \mathrm{~m}$ high and radius of the roof arch was $1.835 \mathrm{~m}$. The explosive charge was placed $2 \mathrm{~m}$ right above the structure and $1.5 \mathrm{~m}$ underground. Study tests focused on examining the distribution of dynamic loads, deflection mode, strain, acceleration, and failure modes of arch structure [13]. Waterways Experiment Station conducted a series of tests, referred to as the Conventional Weapon Effects Backfill (CONWEB) tests, to develop a consistent set of ground shock and structural response data for explosive charges detonated in different soil backfills [14]. In these tests, a $7 \mathrm{~kg}$ pipe-encased C-4 charge was emplaced $1.52 \mathrm{~m}$ from the structure, which composed of a RC slab bolted to a reaction structure [15]. The RC slab was $4.57 \mathrm{~m}$ long and $1.65 \mathrm{~m}$ high [15]. Explosive charge was placed $152.4 \mathrm{~cm}$ away from the slab [15]. The study investigated the pressure, velocity, and displacement on the front slab.

There is limited experimental research on the dynamic response of underground RC structures to subsurface explosion [16], and the extant literature is mostly focused on blast pressure $[17,18]$. A large quantity of experimental studies have examined the impact of far-field subsurface explosions on underground RC structures [19-21]. Additionally, a number of experimental studies have considered other types of underground RC structures such as RC arch structures or RC slabs $[12,14,22]$. Reviews of publications using newer methods of validation of numerical studies through experimental studies, such as finite element updating, indicate the lack of largescale experimental data [23-25]. In using finite element updating method, some researchers have used laboratory results [26, 27]. Usually these results are obtained from shaking table tests [28]. Due to the nature of the finite element updating method, the time-history test data extracted from the large-scale explosion test can help to develop this method.

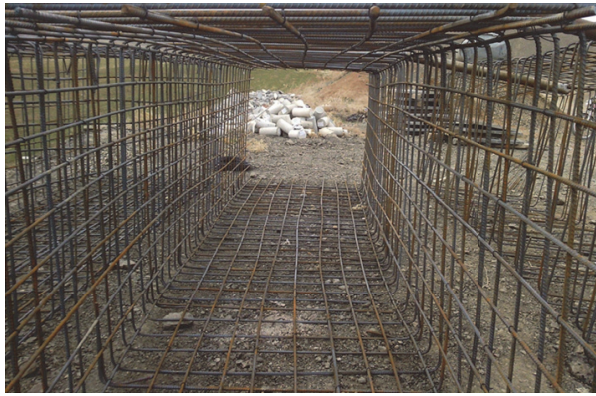

FIgURE 1: Mesh network inside the RC tunnel.

The present study uses two field tests to assess the effects of close-in subsurface explosions on underground RC boxshaped structure. The parameter of interest in this paper is the explosive acceleration on the front wall of RC tunnel structure, a parameter that has been largely neglected in earlier studies. This paper also presents a numerical model that can predict the effect of explosion on acceleration received by $\mathrm{RC}$ structure. In line with the results presented by $\mathrm{Lu}$ et al. [4], the present study uses a two-dimensional numerical model to ultimately assess the effect of changes in shear wave velocity of soil, distance from explosion, and power of explosion on the peak acceleration created in tunnel wall.

\section{Test Method}

2.1. Test Structure. Study tests were performed on a $4 \mathrm{~m}$ long box-shaped tunnel, with two $80 \mathrm{~cm}$ high walls separated by an $80 \mathrm{~cm}$ empty space. Floor, roof, and walls of this box were $10 \mathrm{~cm}$ thick. At the age of 28 days, the average of compressive strength of the concrete for 3 samples was $19 \mathrm{MPa}$ and its tensile strength was assumed to be $1.9 \mathrm{MPa}$. At the age of 42 days, the average of compressive strength of the concrete for the 3 samples was $23 \mathrm{MPa}$ and its tensile strength was assumed to be $2.3 \mathrm{MPa}$. Young's modulus of the concrete was $30 \mathrm{GPa}$ and its specific weight was $2400 \mathrm{~kg} / \mathrm{m}^{3}$.

All concrete components were reinforced by a steel mesh, which was made of $8 \mathrm{~mm}$ steel bars with $100 \mathrm{~mm}$ spacing. The yield strength of the steel bars was $340 \mathrm{MPa}$, and the resulting reinforcement rate was approximately $0.18 \%$ (Figures 1 and 2).

The structure was buried $1.5 \mathrm{~m}$ below the ground. The soil had a specific weight of $1850 \mathrm{~kg} / \mathrm{m}^{3}$ and humidity of $23 \%$. Once buried, the tunnel was open at its two ends, but the openings were closed with sand bags to keep the overhead soil out of the box (Figure 3). Explosive charge was buried $2 \mathrm{~m}$ below the ground surface, exactly $4 \mathrm{~m}$ away from the central axe of the front wall.

Experiment was conducted at 2 stages: (i) Explosion number 1 , created by detonating $1668 \mathrm{gr}$ ammonium nitrate/fuel oil (ANFO) along with 385 gr Gel-Dynamite (Emulite) (1.69 kg equivalent T.N.T. [29]) and (ii) Explosion number 2, created by detonating $2500 \mathrm{gr}$ ANFO along with $578 \mathrm{gr}$ Emulite (2.76 kg equivalent T.N.T. [29]). 

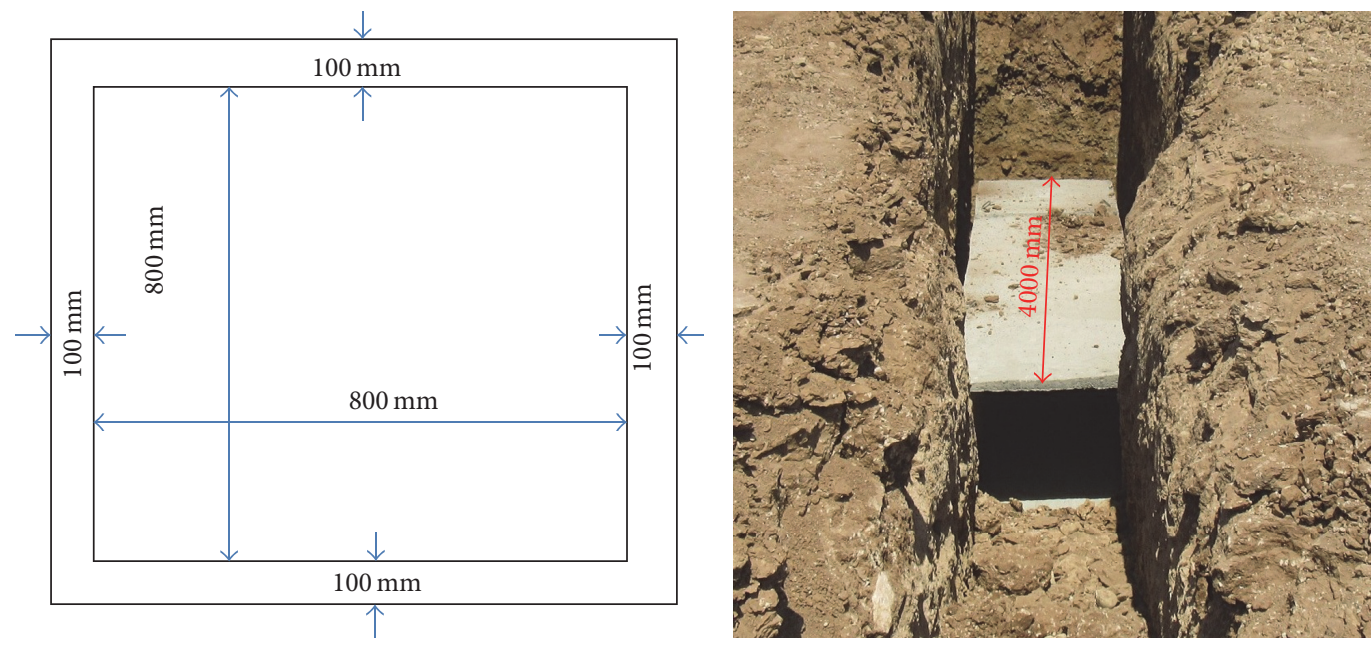

FIGURE 2: Cross section of the tunnel built for experiment.

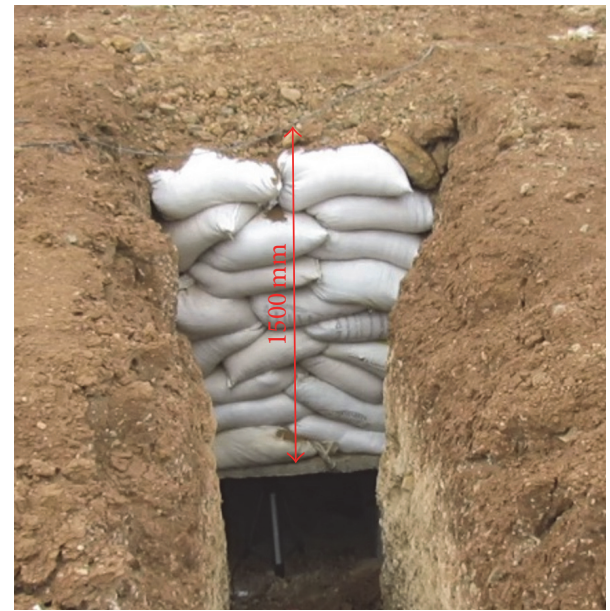

FIGURE 3: The buried tunnel.

2.2. Instrumentation and Measurement. Applied sensors could measure acceleration in one and two directions. The shock survival and resonant frequency of the sensors were $10000 \mathrm{~g}$ and $5.5 \mathrm{kHz}$, respectively. The data logger with four channels was used to record the signals. The sample rate of each channel was $250 \mathrm{MSa} / \mathrm{sec}$ with 12-bit resolution. Cable length was $40 \mathrm{~m}$ without loss of voltage. In order to determine the proper length for the cable, two different lengths of cable were compared for measurement loss of voltage. The cables lengths were 2 and 40 meters. The comparison showed the same results for the voltage. Hence, the 40 -meter cable was used in explosion tests.

The acceleration $10000 \mathrm{~g}$ presents the resonant frequency or the acceleration which cause damage to the sensor. It is noticed, in this test, that two types of sensors are used. The first type consists of the sensors A1 and A3 whose acceleration range is between $-500 \mathrm{~g}$ and $+500 \mathrm{~g}$, while type 2 sensor consists of A2 and A4 whose acceleration range is between $-20 \mathrm{~g}$ and $+20 \mathrm{~g}$. It is noticeable that the changing of voltage of

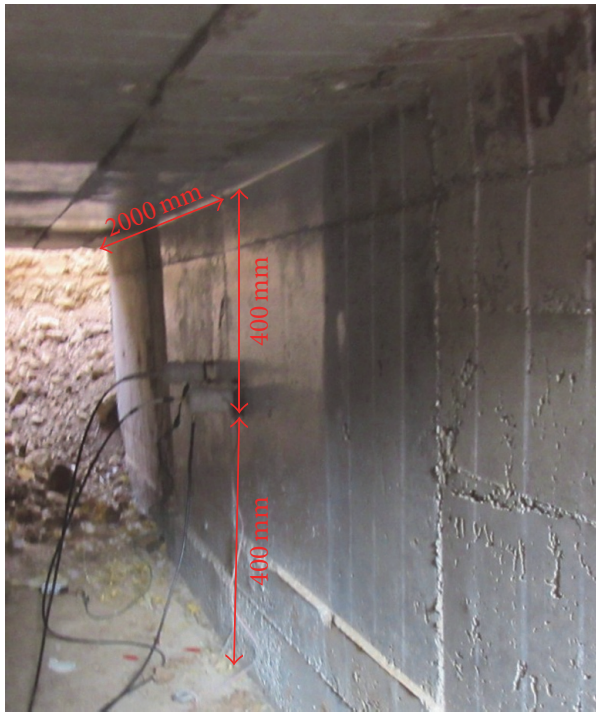

FIGURE 4: Accelerometer sensors installed on the wall of the tunnel.

the sensors type 1 for each $8 \mathrm{mV}$ is equal to the acceleration $1 \mathrm{~g}$. Also the changing of voltage of sensors type 2 for each $175 \mathrm{mV}$ is equal to the acceleration $1 \mathrm{~g}$. As mentioned in the paper, in each test, two types of the sensors were installed on the front wall at points positioned $12.5 \mathrm{~cm}$ away from the central axe of the tunnel and $40 \mathrm{~cm}$ lower than the roof (Figure 4) that consists of two types of the sensors 1 and 2. The comparison of results shows that the recorded accelerations of these two sensors are partly coincident (Figures 5 and 7). Also it is noticed that the data logger used has different adjustable resolution. That is, in this test, the range of recording voltage has been between $-1000 \mathrm{mV}$ and $1000 \mathrm{mV}$. That input voltage of sensor is recorded with the accuracy of $1 \mathrm{mV}$.

A free field sensor was installed at a point on surface $11 \mathrm{~m}$ away from the back wall, on the line crossing the charge location and the central axe of the tunnel. 


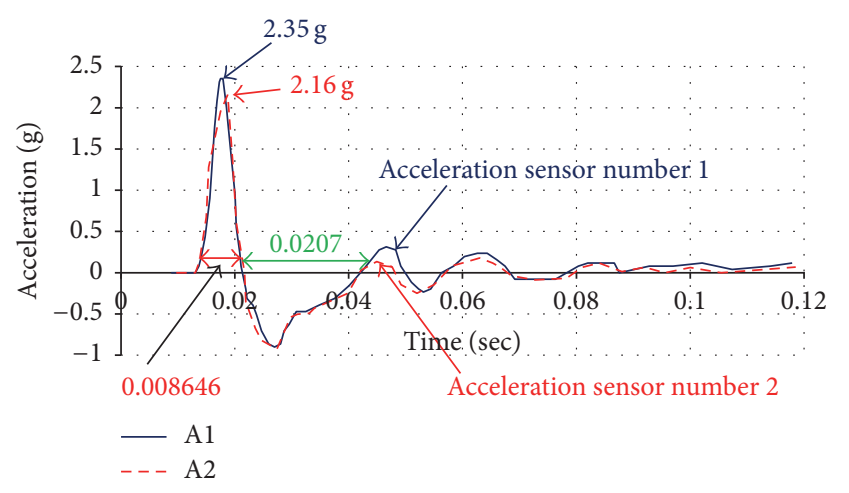

FIgURE 5: The acceleration-time graph for Explosion number 1.

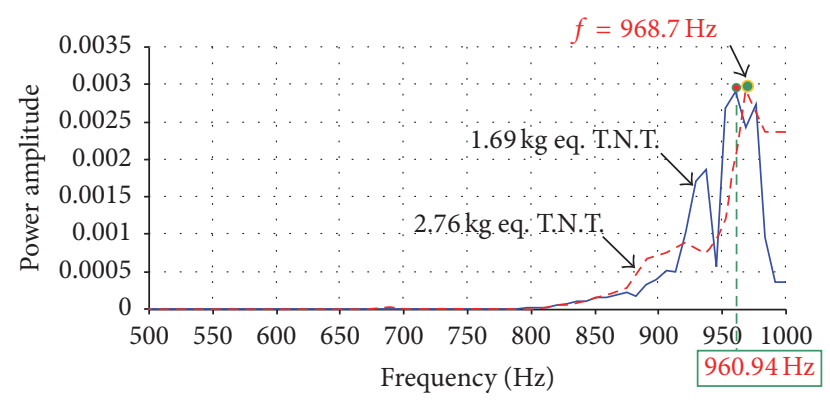

FIGURE 6: Analysis of frequency blast acceleration wave.

\section{Test Results and Discussion}

As mentioned before, two tests were conducted: Explosion number 1, $1.69 \mathrm{~kg}$ equivalent T.N.T, and Explosion number $2,2.76 \mathrm{~kg}$ equivalent T.N.T. The greatest acceleration $(3.00 \mathrm{~g})$ was recorded by sensor A1 in Explosion number 2.

In Explosion number 1, two waves peaked rapidly and created the acceleration of $23.05 \mathrm{~m} / \mathrm{s}^{2}$ in sensor A1. Here, the duration of positive phase was 0.008646 seconds, followed by a negative phase which lasted for $0.0207 \mathrm{sec}$, during which peak acceleration reached $-8.85 \mathrm{~m} / \mathrm{s}^{2}$. Meanwhile, sensor A2 first recorded $0.008649 \mathrm{sec}$ long positive phase with peak acceleration of $21.16 \mathrm{~m} / \mathrm{s}^{2}$ and then a $0.21 \mathrm{sec}$ long negative phase with peak acceleration of $-8.054 \mathrm{~m} / \mathrm{s}^{2}$. After these major positive and negative peaks, acceleration gradually decreased until it reached zero. Figure 5 depicts the results of this test for both channels.

Figure 6 shows that frequencies of the waves which reached the tunnel lining were $968.75 \mathrm{~Hz}$ and $960.94 \mathrm{~Hz}$ for 2.76 and $1.69 \mathrm{~kg}$ equivalent T.N.T. It is noticeable that the frequencies for both tests are within a close range. This phenomenon was predictable because characteristics of the soil-tunnel system were approximately similar for both tests.

As depicted in Figure 7, the wave of Explosion number 2 peaked rapidly and created a $0.007574 \mathrm{sec}$ long positive phase with peak acceleration of $29.43 \mathrm{~m} / \mathrm{s}^{2}$ in sensor A1. It then caused a $0.0239 \mathrm{sec}$ long negative phase with peak acceleration of $-12.53 \mathrm{~m} / \mathrm{s}^{2}$. Meanwhile, sensor A4 first received a $0.007571 \mathrm{sec}$ long positive phase with peak acceleration of $28.65 \mathrm{~m} / \mathrm{s}^{2}$ and then a $0.241 \mathrm{sec}$ long negative phase with peak

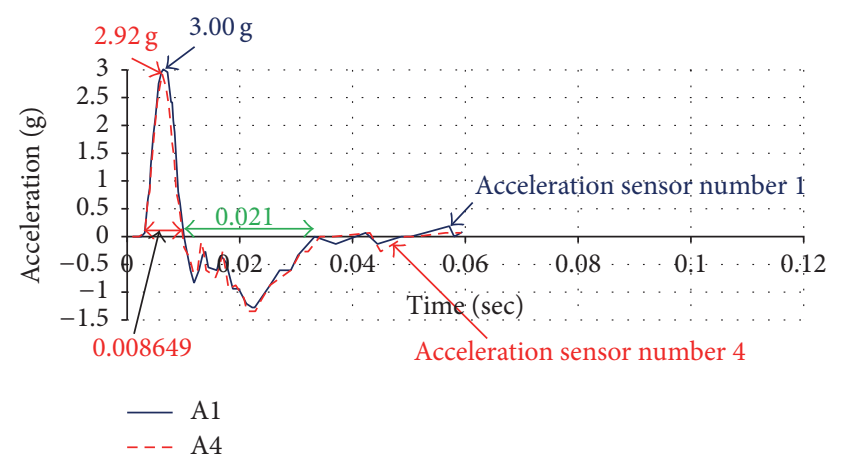

FIgURE 7: The acceleration-time graph for Explosion number 2.

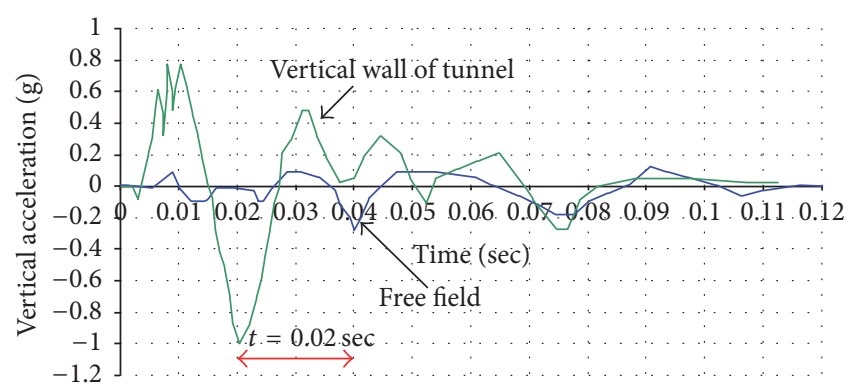

_ Free field vertical component

_ Vertical component on tunnel face

FIgURE 8: The comparison of vertical accelerations between vertical wall of tunnel and free field.

acceleration of $-13.185 \mathrm{~m} / \mathrm{s}^{2}$. So, for sensor A1, the maximum voltage recorded is $24 \mathrm{mV}$ that equals the maximum acceleration $3 \mathrm{~g}$, and, for sensor A4, maximum voltage is $511 \mathrm{mV}$ that equals the acceleration $2.92 \mathrm{~g}$; these two amounts of $24 \mathrm{mV}$ and $511 \mathrm{mV}$ are in range of $-1000 \mathrm{mV}$ to $+1000 \mathrm{mV}$. The comparison of results shows that the recorded accelerations of these two sensors are partly coincident (Figures 5 and 7).

As previously stated, at these positive and negative peaks, acceleration exhibited a decreasing trend. However, the decrease was quicker than the decrease observed in the first test. Figure 8 shows the vertical component of acceleration on the tunnel wall for $2.76 \mathrm{~kg}$ equivalent T.N.T. and also for the free field at $11 \mathrm{~m}$ distance from the tunnel on ground surface. The comparison between the vertical component on the tunnel face and the free field point shows that the peak vertical acceleration decreased from $0.98 \mathrm{~g}$ to $0.28 \mathrm{~g}$. These data can assist in modeling artificial boundaries in numerical analyses of the soil-structure interaction by Lysmer boundaries.

On the other hand, Figure 8 shows that the difference of wave arrival time to tunnel and the free field point at $11 \mathrm{~m}$ from the tunnel is $0.02 \mathrm{sec}$. Therefore, the wave propagation velocity can be calculated equal to $550 \mathrm{~m} / \mathrm{sec}$. Hence, dynamic elasticity shear modules can be determined based on the wave propagation velocity. 


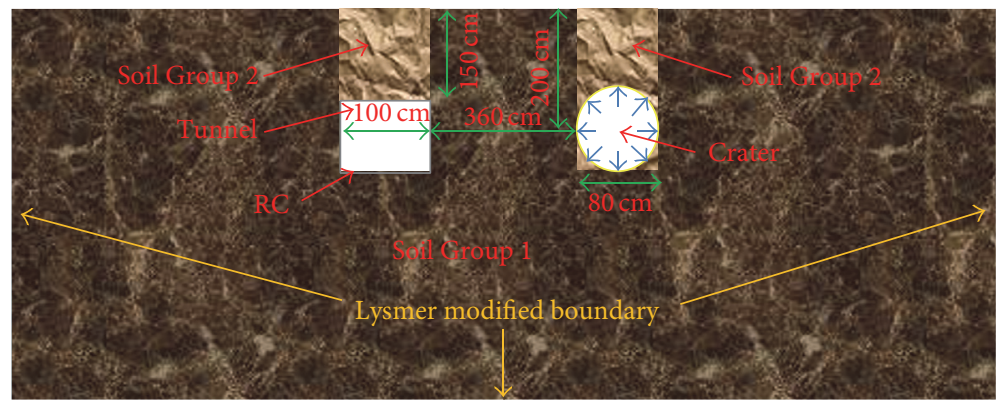

Figure 9: An overview of the numerical model.

\section{Numerical Modeling}

While implementations of different tests are expensive, numerical methods are proper tools to understand and evaluate performance of a designed structure with low costs. Hence, comparison of the results from numerical analysis with field data can help to assess the performance of sensors, data logger, cables, and process of implemented tests. The applied model and its parameters are the only factors in numerical analysis. Soil behavior is linear at low loads [30] and nonlinear at high loads $[31,32]$. Due to the nature of the shock wave of the blast, usually nonlinear models are used for soil $[33,34]$. Due to availability of Mohr-Coulomb model parameters, the Mohr-Coulomb model is more commonly used among all nonlinear models to model the soil [3537]. Akhaveissy et al. [38] proposed the modified generalized plasticity model in finite element method for simulation of different types of soil with hardening/softening behavior and DSC/HISS yield surface. Akhaveissy [39, 40] analyzed soil-tunnel-structure interaction by the modified generalized plasticity model. The comparison between predicted results and field data showed proper correlation for the settlements on the ground surface due to the excavation of Sao Paulo tunnel. Also, predicted results using Mohr-coulomb criterion were in accordance with field data for the case study. The finite element developed code [40] was applied to analyze the dynamic performance of tunnel-soil-superstructure interaction by Lysmer modified boundary. Hence, Mohrcoulomb criterion and modified Lysmer boundaries were used in numerical modeling of the current study. A series of soil mechanics tests based on borehole samples taken from the study site were applied to obtain characteristics of the soil. These characteristics included specific weight, undrained shear strength, and friction angle and are summarized in Table 1 . The tunnel and the crater location were implemented as cut-and-cover method (Figure 9).

Therefore, soil region above the tunnel and the crater location were evaluated as a distributed soil region. Hence, the characteristics of the region using field test results were different from the characteristics of undistributed soil region (Table 1).

In this paper, numerical study that can produce values obtained by the experiment is presented in Figure 10. As indicated earlier, 2D model has been regarded to have acceptable accuracy in predicting the shock wave in soil
TABLE 1: Materials' properties.

\begin{tabular}{|c|c|c|c|}
\hline Materials & Properties & Unit & Value \\
\hline \multirow{5}{*}{ Soil (Group 1) } & Unit mass & $\mathrm{kg} / \mathrm{m}^{3}$ & 1850 \\
\hline & Cohesion & $\mathrm{kPa}$ & 24 \\
\hline & Friction angle & $\circ$ & 31 \\
\hline & Young's modulus & $\mathrm{MPa}$ & 29 \\
\hline & Damping ratio & $\%$ & 2.5 \\
\hline \multirow{5}{*}{ Fill (Group 2) } & Unit mass & $\mathrm{kg} / \mathrm{m}^{3}$ & 1650 \\
\hline & Cohesion & $\mathrm{kPa}$ & 0 \\
\hline & Friction angle & $\circ$ & 20 \\
\hline & Young's modulus & $\mathrm{MPa}$ & 15 \\
\hline & Damping ratio & $\%$ & 2.5 \\
\hline \multirow{5}{*}{ Concrete } & Unit mass & $\mathrm{kg} / \mathrm{m}^{3}$ & 2400 \\
\hline & Young's modulus & $\mathrm{MPa}$ & 30000 \\
\hline & Compressive strength & $\mathrm{MPa}$ & 23 \\
\hline & Tensile strength & $\mathrm{MPa}$ & 2.3 \\
\hline & Yield strain & $\%$ & 0.35 \\
\hline \multirow{3}{*}{ Reinforcement } & Unit mass & $\mathrm{kg} / \mathrm{m}^{3}$ & 7800 \\
\hline & Young's modulus & $\mathrm{MPa}$ & 210000 \\
\hline & Tensile strength & $\mathrm{MPa}$ & 300 \\
\hline \multirow{5}{*}{ Soil-tunnel interface } & Friction & $\circ$ & 20 \\
\hline & Interface resistance & $\mathrm{kPa}$ & 5 \\
\hline & Normal stiffness & $\mathrm{MPa}$ & 315 \\
\hline & Shear stiffness & $\mathrm{MPa}$ & 82 \\
\hline & Tensile strength & $\mathrm{MPa}$ & 1 \\
\hline
\end{tabular}

medium and estimating the blast load and the response of the front wall of a subsurface structure [4]. Therefore, this paper proposed a two-dimensional numerical model to achieve the aforementioned objective.

4.1. Modeling the Tunnel. The structure was modeled by the use of elastic perfectly plastic RC two-noded element. In general, the RC structure is assumed to behave as a linear elastic material with both an axial tensile and compressive failure limit. Plastic behavior is simulated by specifying a limiting plastic moment. The characteristics such as cross-sectional area, specific weight, modulus of elasticity, compressive yield stress, compressive residual stress, tensile yield stress, and tensile residual stresses were used to obtain the numerical model of the element (Table 1). 


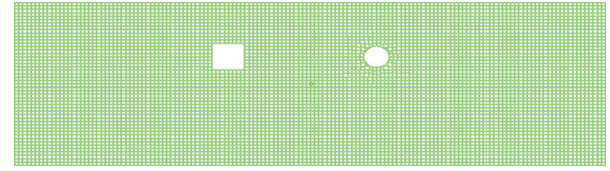

FIGURE 10: Mesh used in numerical analysis.

4.2. Modeling the Soil-Structure Interaction. To assess the possible slippage between the soil and tunnel once they reached a limiting stress, an interface element was defined based on Columbus slippage model and was placed between the soil and the tunnel. Characteristics such as friction angle, interface strength, normal stiffness, and shear stiffness were defined for the element (Table 1).

4.3. Modeling the Blast Load. Blast load can be modeled as an impulse (pressure) [41] with an exponential or triangular quantity-time diagram [5, 41, 42], whose quantity and domain rapidly decrease as it propagates. The quantity of this impulse starts from $P_{0}$ and decreases uniformly over time until it reaches about zero; this decrease is in the form of the following equation $[5,42]$ :

$$
P_{t}=P_{0} e^{-t / a}
$$

where $P_{t}$ is the blast pressure at time $t$. It should be noted that the time of arrival $t_{a}$ is inversely proportional to the velocity of the wave. As such, an explosion in a soil medium with high wave propagation velocity (such as saturated clay) creates high-frequency and high-acceleration waves with small displacements $[5,42]$.

Increasing the explosive charge increases the dynamic load at all points. The maximum dynamic force $P_{0}$ has been obtained from semiempirical equation provided by US Army $[5,42]$ :

$$
P_{0}=48.8 \rho C f_{c}\left(\frac{2.52 R}{W^{1 / 3}}\right)^{-n},
$$

where $\rho$ is the specific density of the soil $\left(1850 \mathrm{~kg} / \mathrm{m}^{3}\right), C$ is the average wave velocity $(550 \mathrm{~m} / \mathrm{s}), R$ is the distance from the explosive charge $(4 \mathrm{~m}), W$ is the weight of explosive charge $(1.76 \mathrm{~kg}, 2.69 \mathrm{~kg})$, and $n$ is the damping coefficient, which is 2.5 for sandy clay [5].

In this model, a crater positioned was defined at a point $4 \mathrm{~m}$ away from the front wall and $2 \mathrm{~m}$ below the surface. Then, the blast load to this crater was applied.

\section{Comparing the Results of Numerical Study with Experimental Results}

To validate the numerical study, its results were compared with the results obtained from the empirical tests. Figures 11 and 12 show the test results along with the results obtained from the numerical model for both explosions.

As depicted in Figure 11, the wave of Explosion number 1 peaked rapidly. It remained $0.0087 \mathrm{sec}$ in positive phase, during which it reached a peak acceleration of $22.27 \mathrm{~m} / \mathrm{s}^{2}$.

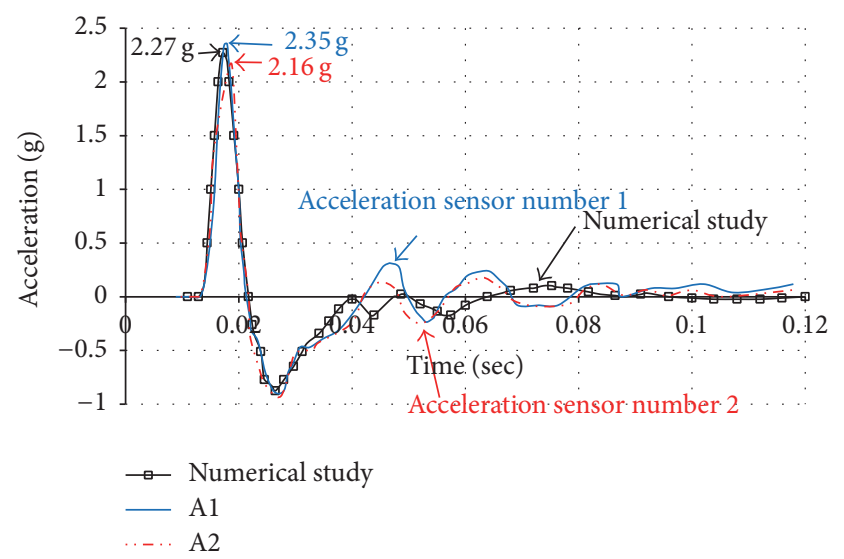

FIGURE 11: Comparison between the acceleration-time graphs obtained from the numerical model and the experimental results (Explosion number 1).

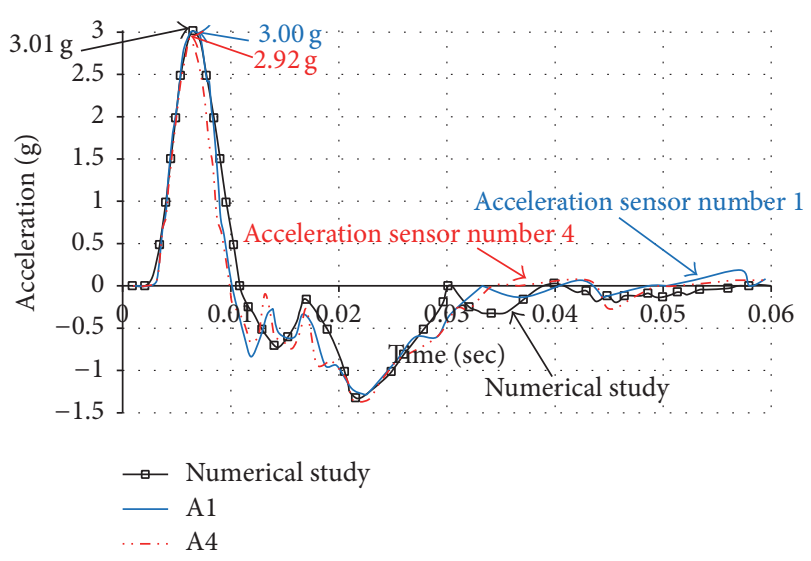

FIGURE 12: Comparison between the acceleration-time graphs obtained from the numerical model and the experimental results (Explosion number 2).

This wave then proceeded to negative phase, which lasted for $0.018 \mathrm{sec}$, during which the wave reached a peak acceleration of $-7.35 \mathrm{~m} / \mathrm{s}^{2}$. According to Figure 12, the wave of Explosions number 2 remained in positive phase for $0.008 \mathrm{sec}$, during which it reached a peak acceleration of $29.53 \mathrm{~m} / \mathrm{s}^{2}$. This wave then moved to negative phase, which lasted for $0.018 \mathrm{sec}$ and reached a peak acceleration of $-12.82 \mathrm{~m} / \mathrm{s}^{2}$. As shown in Figures 9 and 10, results of the numerical model are completely consistent with the experimental data.

Figures 13-15 show the distribution of acceleration, velocity, and displacement caused by Explosions numbers 1 and 2. For all of the three parameters, the highest values were obtained in the middle of the wall and the lowest values were recorded in the upper corner.

The proposed numerical model was also used to study the effect of changes in cross section of the tunnel, shear wave velocity of the soil, and changes in the profile of explosion on the acceleration received in tunnel wall.

The numerical study was used to determine the effect of shear wave velocity of soil on the peak acceleration in the 


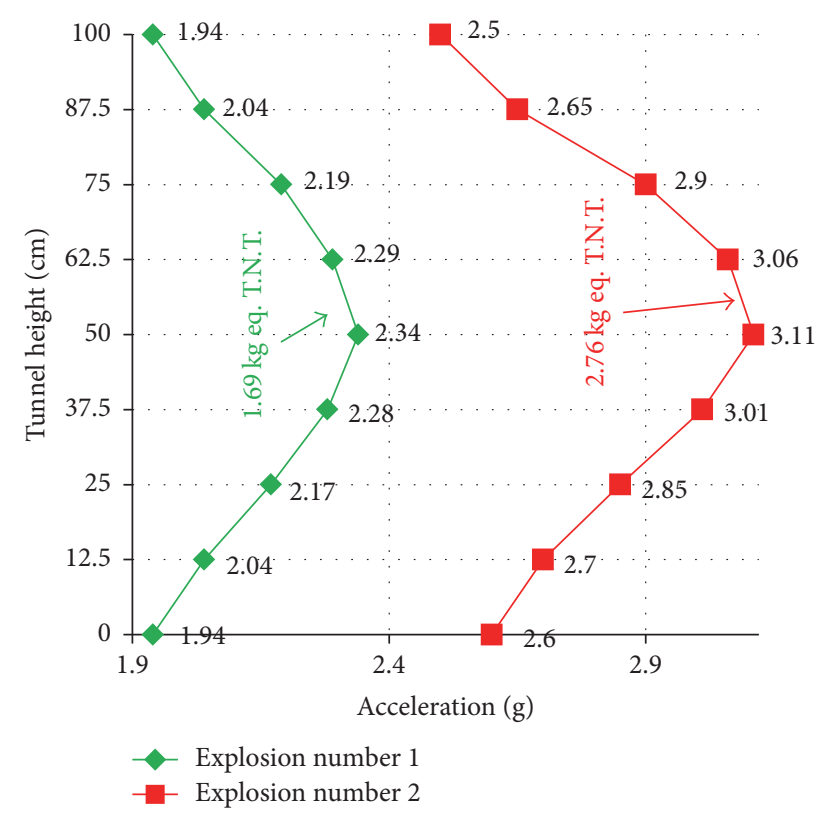

FIGURE 13: Distribution of acceleration on the front wall caused by Explosions numbers 1 and 2.

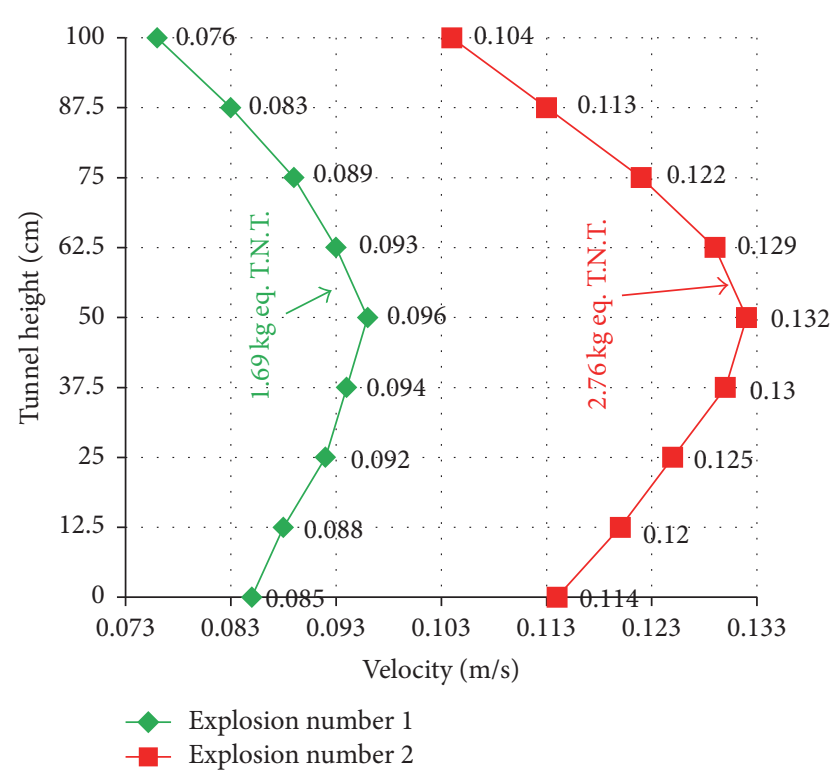

FIgURE 14: Distribution of velocity on the front wall caused by Explosions numbers 1 and 2.

tunnel wall. This was achieved through changing the shear wave velocity of the soil to the range of 200 to $2000 \mathrm{~m} / \mathrm{s}$, while keeping other parameters fixed.

Figure 16 shows the results obtained from this process. It can be observed that as shear wave velocity increases in both Explosions numbers 1 and 2, the acceleration (created in the front wall) first slightly increases but then exhibits a decreasing trend. The maximum acceleration was obtained for shear wave velocity of $400 \mathrm{~m} / \mathrm{s}$.

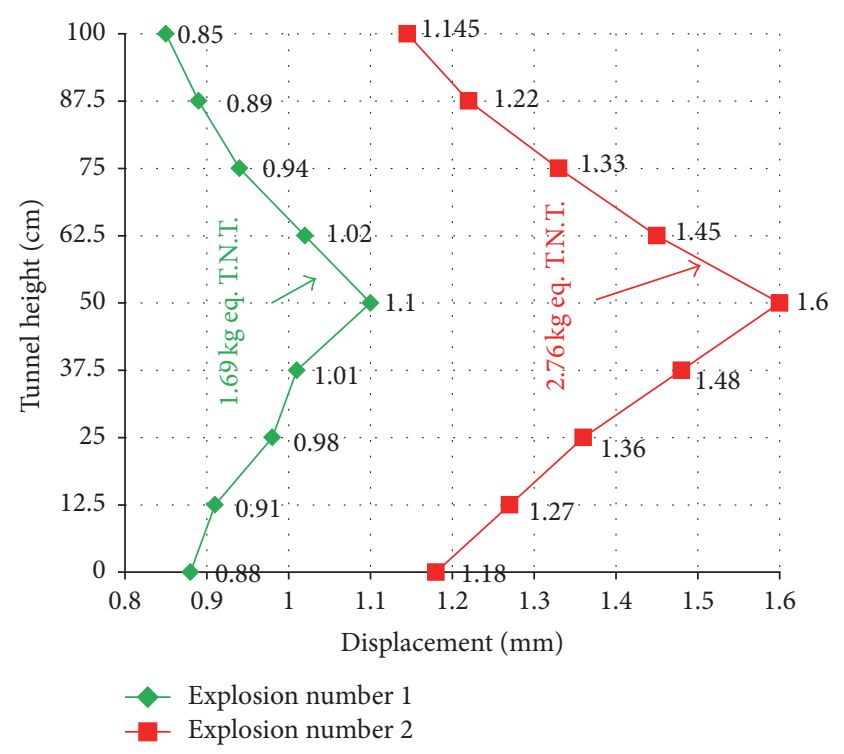

FIGURE 15: Distribution of displacement on the front wall caused by Explosions number 1 and 2.

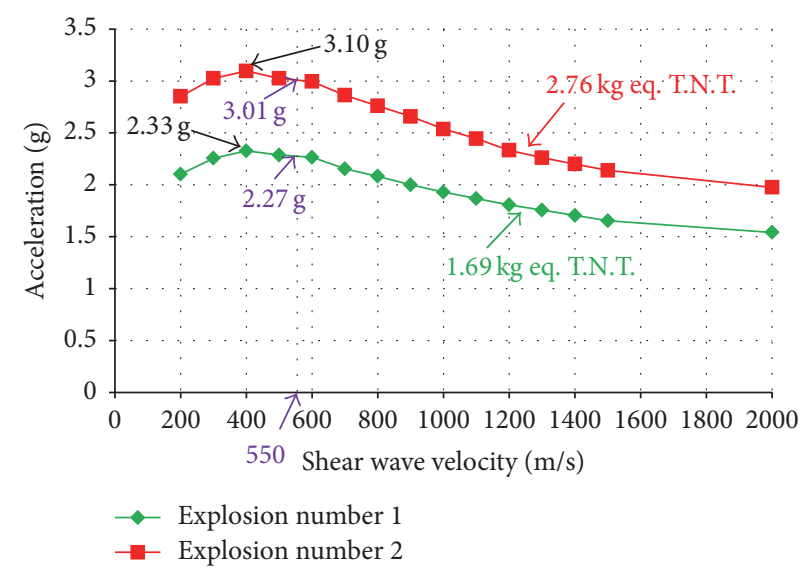

FIGURE 16: The graph of peak acceleration in the front wall versus shear wave velocity of soil.

The effect of distance from explosion on the peak acceleration received in the tunnel wall was investigated by using numerical study. To achieve this objective, the location of crater was changed in the range between 2 and $6 \mathrm{~m}$ away from the front wall and the effects of these changes were studied in the peak acceleration. Figure 17 shows the results obtained from this process and indicates that the acceleration created in the wall aggressively increases as explosion gets closer but decreases gradually as explosion gets farther.

The last parameter studied by the numerical study was the effect of explosion power on the peak acceleration received in the front wall of the tunnel. Here, Explosion number 1 was used as a metric, and explosions with 1.5, 2, 2.5, 3, 3.5, and 4 times its power were studied. Results showed that as power of explosion increases, peak acceleration in front wall increases with an almost constant slope (Figure 18). 


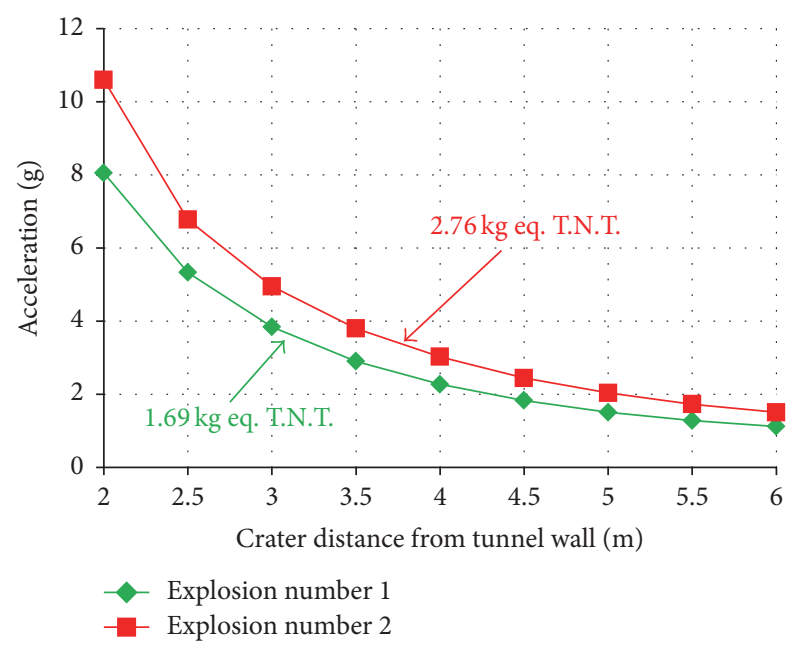

FIGURE 17: The graph of peak acceleration in the front wall versus distance from the explosion.

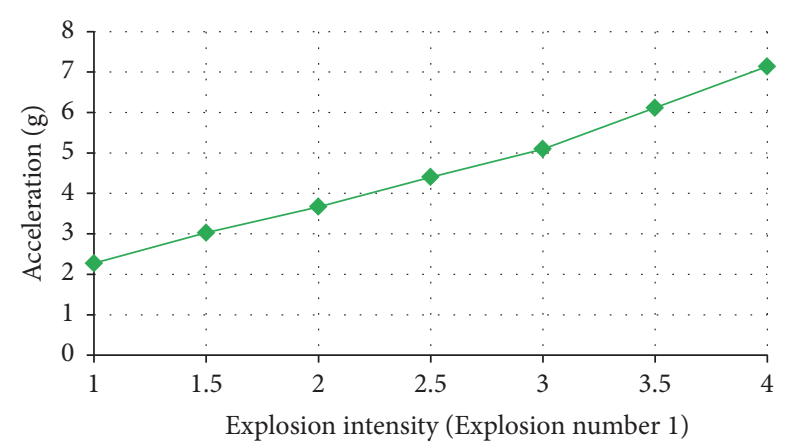

FIgURE 18: The graph of peak acceleration in the front wall versus explosion intensity.

\section{Conclusion}

This paper presented the results of a close-in subsurface explosion field experiment conducted on a buried $4 \times 1 \mathrm{~m}$ $\times 1 \mathrm{~m}$ box-shape tunnel, using explosive charges of $1.69 \mathrm{~kg}$ and $2.76 \mathrm{~kg}$ equivalent T.N.T., respectively. The horizontal and vertical accelerations were recorded on the vertical wall of the tunnel and also the free field data including the acceleration on the ground surface. The experimental results which have not been presented in previous studies are helpful for engineers and support further theoretical and numerical analysis. A numerical study was also conducted using the finite element developed code to obtain the graphs representing the distribution of acceleration, velocity, and displacement at the front wall of the tunnel. Parameters studied by this numerical study included effect of changes in shear wave velocity of soil, distance from explosion, and power of explosion on the peak acceleration at the center of tunnel's front wall. Results of numerical study showed that the received acceleration increases slowly with shear wave velocity of soil and peaks at shear wave velocity of $400 \mathrm{~m} / \mathrm{s}$, but it then exhibits a steady downward trend. Numerical results regarding the effect of distance from the explosion revealed that the received acceleration aggressively increases as explosion gets closer to the wall but decreases gradually as explosion gets farther. The results also demonstrated that as the power of explosion increases, peak acceleration received in the front wall increases with an almost constant slope.

\section{Competing Interests}

The authors declare that they have no competing interests.

\section{Acknowledgments}

In light of the fact that no governmental or nongovernmental organization was willing to provide the financial means to carry out this work, the authors feel it incumbent upon themselves to extend their deep gratitude to Jahad Nasr Company of Kermanshah province, who were in the process of mining stone material to finish an embankment dam, for their gracious cooperation in helping with the explosion tests.

\section{References}

[1] W. A. M. Alwis and K. Y. Lam, "Response spectrum of underground protective structures," Finite Elements in Analysis and Design, vol. 18, no. 1-3, pp. 203-209, 1994.

[2] E. E. Hinman, "Effect of deformation on the shock response of buried structures subject to explosions," in Structures under Shock and Impact, pp. 455-465, Elservier, New York, NY, USA, 1989.

[3] D. J. Stevens and T. Krauthammer, "A finite difference/finite element approach to dynamic soil-structure interaction modelling," Computers \& Structures, vol. 29, no. 2, pp. 199-205, 1988.

[4] Y. Lu, Z. Wang, and K. Chong, "A comparative study of buried structure in soil subjected to blast load using 2D and 3D numerical simulations," Soil Dynamics and Earthquake Engineering, vol. 25, no. 4, pp. 275-288, 2005.

[5] U.S. Department of the Army, "Fundamentals of protective design for conventional weapons," Tech. Rep. TM5-855-1, US Army Engineers Waterways Experimental Station, Vicksburg, Miss, USA, 1986.

[6] M. W. Gui and M. C. Chien, "Blast-resistant analysis for a tunnel passing beneath Taipei Shongsan airport-a parametric study," Geotechnical and Geological Engineering, vol. 24, no. 2, pp. 227248, 2006.

[7] Z. Yang, "Finite element simulation of response of buried shelters to blast loadings," Finite Elements in Analysis and Design, vol. 24, no. 3, pp. 113-132, 1997.

[8] V. D. Alekseenko and G. V. Rykov, "Experimental data on stresswave parameters in the earth due to underground and surface explosions," Journal of Applied Mechanics and Technical Physics, vol. 9, no. 4, pp. 409-411, 1968.

[9] S. S. Grigoryan, G. M. Lyakhov, and P. A. Parshukov, "Spherical blast waves in soils inferred from stress and strain measurements," Journal of Applied Mechanics and Technical Physics, vol. 18, no. 1, pp. 124-127, 1977.

[10] D. Z. Yankelevsky, V. R. Feldgun, and Y. S. Karinski, "Underground explosion of a cylindrical charge near a buried wall," International Journal of Impact Engineering, vol. 35, no. 8, pp. 905-919, 2008. 
[11] A. A. Vovk, I. A. Luchko, G. M. Lyakhov, V. A. Plaksii, and N. S. Remez, "Cylindrical blast waves in soils," Journal of Applied Mechanics and Technical Physics, vol. 27, no. 4, pp. 571-576, 1986.

[12] J. An, Soil behavior under blast loading [Ph.D. thesis], Civil Engineering Department, University of Nebraska, Lincoln, NE, USA, 2010.

[13] H. L. Chen, J. N. Zhou, H. L. Fan et al., "Dynamic responses of buried arch structure subjected to subsurface localized impulsive loading: experimental study," International Journal of Impact Engineering, vol. 65, pp. 89-101, 2014.

[14] P. G. Hayes, Backfill effects on response of buried reinforced concrete slabs [M.S. thesis], Waterways Experiment Station, Corps of Engineers, Vicksburg, Miss, USA, 1989.

[15] G. C. Bessette, "Modeling coupled blast/structure interaction with zapotec," in Benchmark Calculations for the Conventional Weapon Effects Backfill (CONWEB) Tests, Sandia National Laboratories, Livermore, Calif, USA, 2004.

[16] Y. S. Karinski, V. R. Feldgun, and D. Z. Yankelevsky, "Shock waves interaction with a single inclusion buried in soil," International Journal of Impact Engineering, vol. 45, pp. 60-73, 2012.

[17] C. Wu, Y. Lu, H. Hao, W. K. Lim, Y. Zhou, and C. C. Seah, "Characterisation of underground blast-induced ground motions from large-scale field tests," Shock Waves, vol. 13, no. 3, pp. 237-252, 2003.

[18] H. Yu, Y. Yuan, G. Yu, and X. Liu, "Evaluation of influence of vibrations generated by blasting construction on an existing tunnel in soft soils," Tunnelling and Underground Space Technology, vol. 43, pp. 59-66, 2014.

[19] J. P. Balsara, "Similitude study of flexible buried arches subjected to blast loads," Tech. Rep. 1-807, U.S.A.C.E. Waterways Experiment Station, Vicksburg, Misss, USA, 1968.

[20] W. J. Flathau, R. A. Breckenridge, and C. K. Wiehle, "Blast loading and response of underground concrete arch protective structures," Tech. Rep. ITR-1420, Operation Plumbob-Project 3.1, U.S.A.C.E. Waterways Experiment Station, Vicksburg, Misss, USA, 1957.

[21] R. E. Grubaugh, "Full scale field tests of dome and arch structures," Tech. Rep. ITR-I425, Operation Plumbob-Project 3.6, Air Force Special Weapons Center, Albuquerque, NM, USA, 1975.

[22] W. Xie, M. Jiang, H. Chen et al., "Experimental behaviors of CFRP cloth strengthened buried arch structure subjected to subsurface localized explosion," Composite Structures, vol. 116, no. 1, pp. 562-570, 2014.

[23] J. M. W. Brownjohn, P.-Q. Xia, H. Hao, and Y. Xia, "Civil structure condition assessment by FE model updating: methodology and case studies," Finite Elements in Analysis and Design, vol. 37, no. 10, pp. 761-775, 2001.

[24] J. E. Mottershead, M. Link, and M. I. Friswell, “The sensitivity method in finite element model updating: a tutorial," Mechanical Systems and Signal Processing, vol. 25, no. 7, pp. 2275-2296, 2011.

[25] V. K. Chillara, B. Ren, and C. J. Lissenden, "Guided wave mode selection for inhomogeneous elastic waveguides using frequency domain finite element approach," Ultrasonics, vol. 67, pp. 199-211, 2016.

[26] S.-S. Jin, S. Cho, H.-J. Jung, J.-J. Lee, and C.-B. Yun, "A new multi-objective approach to finite element model updating," Journal of Sound and Vibration, vol. 333, no. 11, pp. 2323-2338, 2014.
[27] C. Liu, J. Miao, and C. Zhao, "Finite element model fractional steps updating strategy for spatial lattice structures based on generalized regression neural network," Shock and Vibration, vol. 2016, Article ID 5845326, 10 pages, 2016.

[28] Z. X. Yuan and K. P. Yu, "Finite element model updating of damped structures using vibration test data under base excitation," Journal of Sound and Vibration, vol. 340, pp. 303316, 2015.

[29] P. W. Cooper, Explosives Engineering, John Wiley \& Sons, New York, NY, USA, 1996.

[30] P. Dangla, "A plane strain soil-structure interaction model," Earthquake Engineering \& Structural Dynamics, vol. 16, no. 8, pp. 1115-1128, 1988.

[31] P. Weidlinger and E. Hinman, "Analysis of underground protective structures," Journal of Structural Engineering, vol. 114, no. 7, pp. 1658-1673, 1988.

[32] R. De Boer, "On plastic deformation of soils," International Journal of Plasticity, vol. 4, no. 4, pp. 371-391, 1988.

[33] L. B. Jayasinghe, D. P. Thambiratnam, N. Perera, and J. H. A. R. Jayasooriya, "Blast response and failure analysis of pile foundations subjected to surface explosion," Engineering Failure Analysis, vol. 39, pp. 41-54, 2014.

[34] M. Saleh and L. Edwards, "Evaluation of soil and fluid structure interaction in blast modelling of the flying plate test," Computers \& Structures, vol. 151, pp. 96-114, 2015.

[35] D. M. Fox, X. Huang, D. Jung, W. L. Fourney, U. Leiste, and J. S. Lee, "The response of small scale rigid targets to shallow buried explosive detonations," International Journal of Impact Engineering, vol. 38, no. 11, pp. 882-891, 2011.

[36] L. Tian and Z.-X. Li, "Dynamic response analysis of a building structure subjected to ground shock from a tunnel explosion," International Journal of Impact Engineering, vol. 35, no. 10, pp. 1164-1178, 2008.

[37] A. Neuberger, S. Peles, and D. Rittel, "Scaling the response of circular plates subjected to large and close-range spherical explosions. Part II: buried charges," International Journal of Impact Engineering, vol. 34, no. 5, pp. 874-882, 2007.

[38] A. H. Akhaveissy, C. S. Desai, S. A. Sadrnejad, and H. Shakib, "Implementation and comparison of a generalized plasticity and disturbed state concept for the load-deformation behavior of foundations," Scientia Iranica, Transaction A: Civil Engineering, vol. 16, no. 3, pp. 189-198, 2009.

[39] A. H. Akhaveissy, "Analysis of tunnel and super structures for excavation," Scientia Iranica, vol. 18, no. 1, pp. 1-8, 2011.

[40] A. H. Akhaveissy, Evaluation of tunnel-structure interaction due to strong ground movement [Ph.D. thesis], Civil Engineering Department, Tarbiat Modares University, Tehran, Iran, 2007.

[41] P. D. Smith and J. G. Hetherington, Blast and Ballistic Loading of Structures, Butterworth-Heinemann, Oxford, UK, 1994.

[42] US Army Corps, "Structures to resist the effects of accidental explosion," Tech. Rep. Army TM 5-1300, Navy NAVFAC P-397, AFR 88-22, Departments of the Army, Navy, and Air Force, Washington, DC, USA, 1990. 


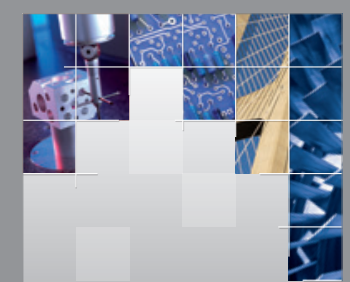

\section{Enfincering}
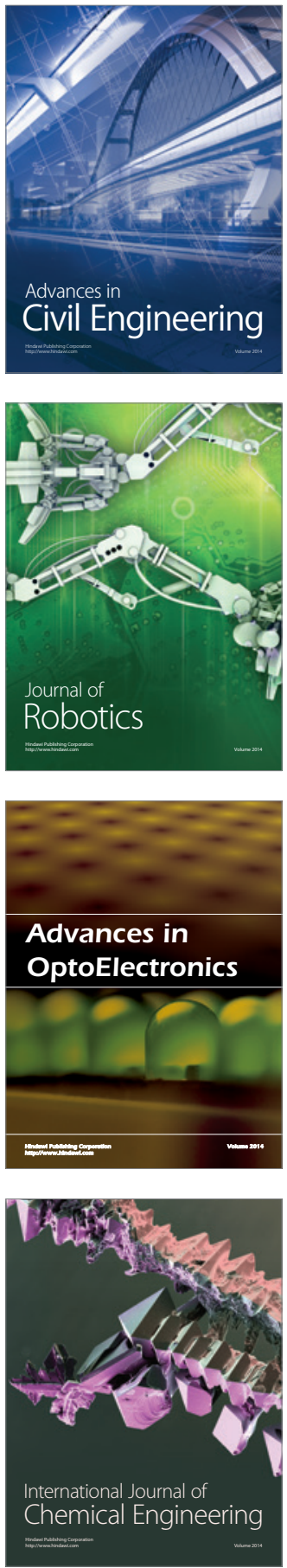

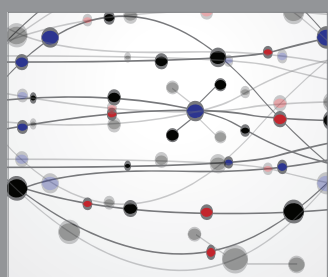

The Scientific World Journal

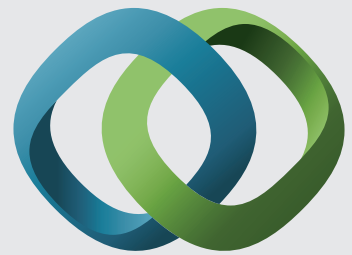

\section{Hindawi}

Submit your manuscripts at

http://www.hindawi.com
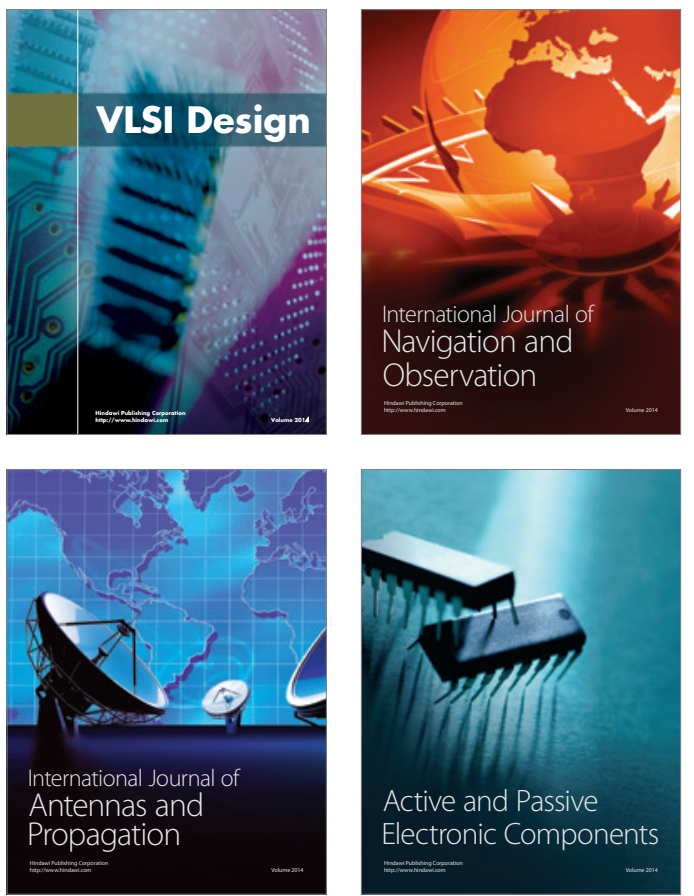
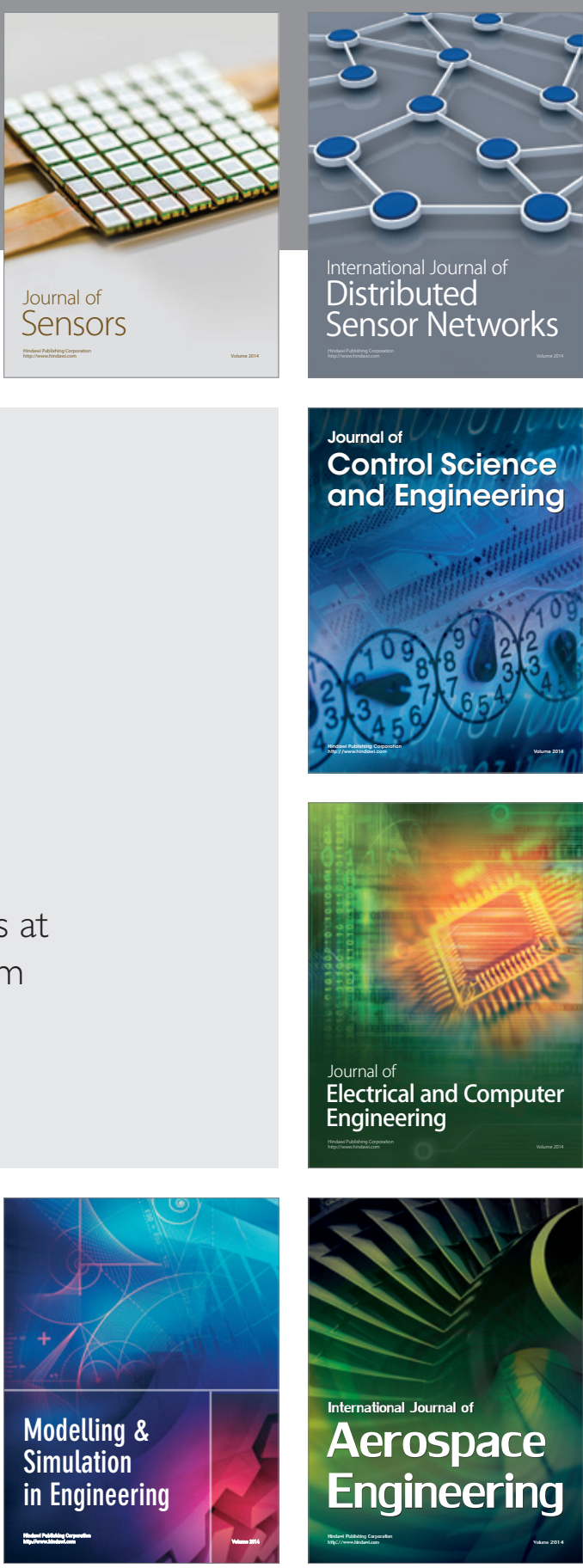

International Journal of

Distributed

Sensor Networks

Journal of

Control Science

and Engineering
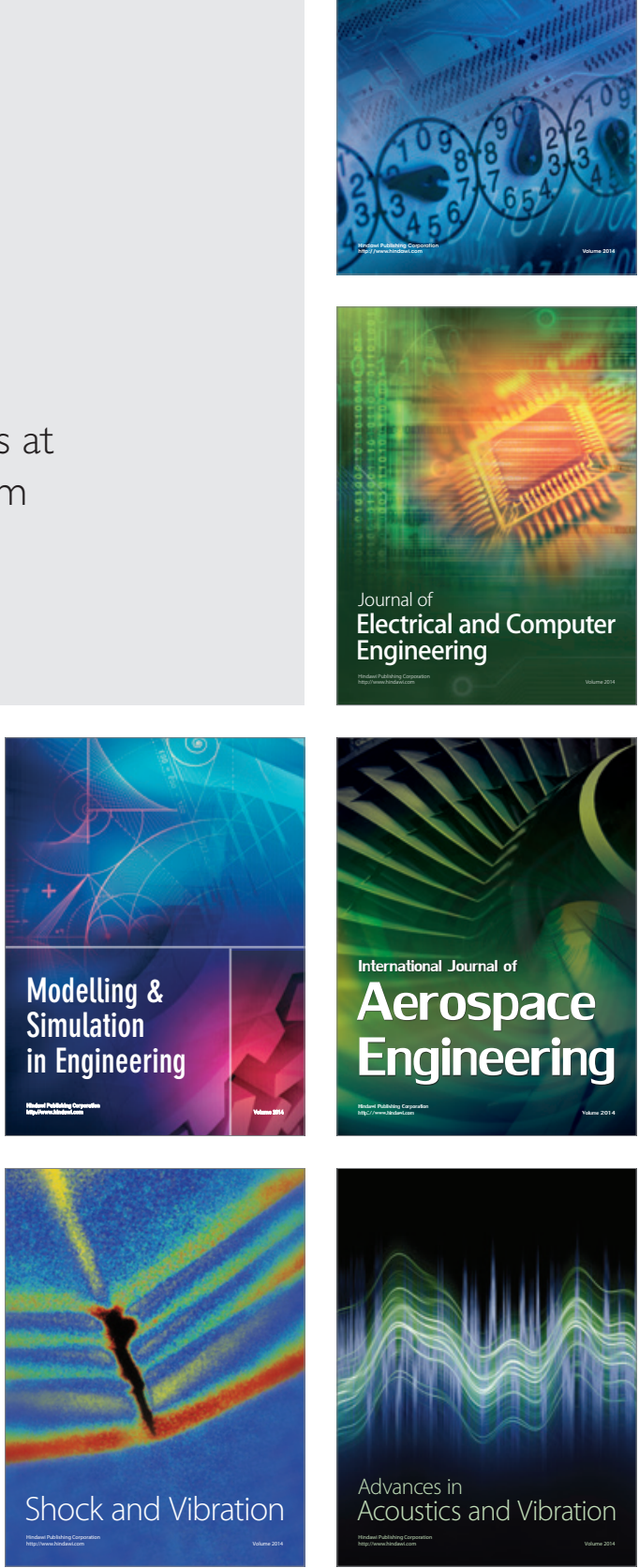